INVESTIGACIONES

de HISTORIA ECONÓMICA

2008, primavera, número 11. Pp. 137 a 164

\title{
¿Proyecto faraónico o chivo expiatorio? \\ La IV Planta Siderúrgica Integral de Sagunto (1966-1977)
}

\author{
An imperial project or a scapegoat? \\ The Fourth Integrated Steel Plant of Sagunto (1966-1977)
}

\author{
PABLO DÍAZ MORLÁN \\ ANTONIO ESCUDERO GUTIÉRREZ \\ MIGUEL ÁNGEL SÁEZ GARCÍA \\ Universidad de Alicante
}

RESUMEN

El objeto de este trabajo es analizar las razones de la creación de la IV Planta Siderúrgica Integral de Sagunto, a partir de fuentes de archivo, para demostrar que se trató de una decisión racional e inspirada en las experiencias de los países del entorno. La clave de dicha decisión, y el principal argumento de crítica posterior, fue la elaboración de un estudio de mercado que estimó erróneamente el consumo futuro nacional de productos siderúrgicos. Pero no se debe atribuir tal error a supuestas pretensiones faraónicas del régimen de Franco, sino al carácter imprevisible de la crisis económica de la década de 1970 y a las profundas consecuencias que tuvo sobre el sector siderúrgico en todo el mundo.

PALABRAS CLAVE: Demanda de Acero, Crisis, España, Sagunto, IV Planta Siderúrgica

Códigos JEL: L61, N64

\begin{abstract}
The aim of this article is to analyse the reasons for the creation of the Fourth Integrated Steel Plant in Sagunto. Using primary sources, we demonstrate that it was a rational decision that imitated the experience of other developed countries. This decision was based on a market study that failed in its steel consumption forecast. But such error was not due to the imperial dreams of Franco's regime, but to the unforeseeable character of the 1970's economic crisis and its effects on the steel industry.
\end{abstract}

KEY WORDS: Fourth Integrated Steel Plant, Spain, Sagunto, Crisis, Steel Demand

JEL Codes: L61, N64 


\section{Introducción ${ }^{1}$}

comienzos de 1983, el gobierno socialista, recién salido de las urnas, hubo de tomar una decisión difícil sobre la reconversión de la siderurgia integral. De 1 las tres provincias afectadas, Asturias, Vizcaya y Valencia, fue esta última la que salió perjudicada de una distribución de fondos que para muchos estuvo guiada más por criterios políticos que empresariales. El origen principal de las críticas provino del hecho de que el nuevo ministro de Industria, Carlos Solchaga, desechó el informe que la Kawasaki Steel Corporation había elaborado a petición de los anteriores mandatarios de la UCD, que recomendaba potenciar Altos Hornos del Mediterráneo en detrimento de ENSIDESA y, sobre todo, de Altos Hornos de Vizcaya. El ejecutivo dio la vuelta a las conclusiones de dicho informe y decidió destinar el grueso de las subvenciones y créditos a salvar las fábricas del norte. Se extendió entonces el exitoso argumento de que la IV Planta Siderúrgica Integral de Sagunto (IV PSI, en adelante) había sido un fruto tardío y desgraciado del espíritu faraónico dominante en el régimen de Franco. De este modo, la siderurgia mediterránea carecía por completo de sentido económico y la decisión de no invertir en ella estaba plenamente justificada y contribuía a corregir los excesos imperiales del tardofranquismo ${ }^{2}$.

Este trabajo analiza las razones de la creación de la IV Planta Siderúrgica Integral mediante documentación procedente de cuatro archivos e intenta demostrar que el citado argumento constituye un ejemplo de "presentismo" que distorsiona el pasado al estar influido por las circunstancias del momento en que apareció ${ }^{3}$. Las graves preocupaciones que dominaban a empresarios, economistas y gobernantes en

[Fecha de recepción del original, mayo de 2007. Versión definitiva, diciembre de 2007]

1 Este trabajo se ha beneficiado de un proyecto de I+D de la Consejería de Empresa, Universidad y Ciencia de la Generalitat Valenciana (GV05/156). Queremos agradecer la colaboración de los responsables de la Fundación para la Protección del Patrimonio Histórico Industrial de Sagunto, Juan Vicente Beltrán y Pablo Vila, así como las sugerencias y comentarios de los cinco evaluadores anónimos de Investigaciones de Historia Económica.

2 García Crespo, Velasco y Mendizábal (1981), pp. 369 y 373; Sánchez-Reyes (1983); El País, 18/07/83; e Instituto Nacional de Industria (1984). Esta interpretación ha sobrevivido al paso de los años y ha llegado hasta fechas recientes, como puede verse en los trabajos de Navarro (1988) y (1989); Catalan (2002) y (2003); y Binda (2005). El Presidente de Altos Hornos de Vizcaya (AHV), Juan Luis Burgos, calificó en 1982 de faraónicos los proyectos de la Administración relacionados con la siderurgia pública en un momento en que la empresa vasca competía con ENSIDESA por los fondos destinados a la reconversión (Altos Hornos de Vizcaya, 1982). Burgos había sido el director financiero de la compañía durante la construcción de la IV Planta en Sagunto y uno de sus mayores defensores, como veremos más adelante.

3 En concreto, hemos recurrido a la documentación conservada en el Archivo General de la Administración (AGA, en adelante), en el Archivo de Protección Patrimonio Historia Industrial de Sagunto (AS, en adelante), en el Fondo Altos Hornos de Vizcaya del Archivo Foral de Vizcaya (AFV, en adelante) y en el Archivo del Banco Bilbao Vizcaya Argentaria (ABBVA, en adelante). 
torno al problema de la supervivencia del sector siderúrgico en la década de 1980 llevaron en ocasiones a buscar en el régimen anterior a los culpables de la crisis. El franquismo se convirtió así en chivo expiatorio.

Para analizar la historia de una inversión que, según el Instituto de Promoción Industrial de Valencia, fue el mayor proyecto industrial de España -126.665 millones de pesetas ${ }^{4}$ - , hemos dividido el trabajo en tres partes, además de las conclusiones. Analizamos, primero, las razones que justificaron la decisión de construir una nueva planta en Sagunto. Estudiamos, después, la concesión y ejecución de su primera fase y, en la tercera parte, explicamos las causas de su abrupta interrupción. La documentación consultada nos permite sostener la conclusión de que aquello que en la década de 1980 pudo parecer una idea descabellada a la vista de la crisis siderúrgica, no lo era en 1966. El proyecto apoyado entonces por el Estado y emprendido por Altos Hornos de Vizcaya (AHV), la United States Steel (USS) y lo más granado de la banca española fue lógico y meditado, y estuvo inspirado en la experiencia de otros países de la OCDE.

Antes de entrar en materia, debemos indicar que el proyecto de Sagunto derivó de una política económica cuya bondad ha sido objeto de debate y en cuya conveniencia o inconveniencia no entramos en un trabajo que sólo pretende demostrar la racionalidad de una medida adoptada dentro de ese marco institucional.

\section{La justificación de una nueva siderurgia integral en Sagunto (1966-1971)}

La clave de la decisión de construir una nueva planta siderúrgica en España, y el principal argumento de crítica posterior, fue la elaboración de un estudio de mercado estimando el consumo futuro nacional de productos siderúrgicos. Establecidas las necesidades del país, bastaba contrastarlas con la capacidad de producción de las empresas existentes, incluyendo las ampliaciones acogidas a la Acción Concertada, para calcular el déficit que, si no se remediaba, debería cubrirse con importaciones, con la consiguiente salida de divisas. Era, pues, fundamental que la estimación del consumo de los años venideros se realizara con las máximas garantías posibles. De ello fue plenamente consciente la Administración, que, desde el Programa Siderúrgico Nacional de 1964, recurrió a técnicas empleadas en el extranjero que fue perfeccionando y corrigiendo en sucesivas revisiones ${ }^{5}$. Los especialistas emplearon ratios

AS, IPIV, p. 164.

Véase Cavallé (1975), pp. 138-152, para una explicación de la elaboración y revisión del Programa Siderúrgico Nacional. 
habituales en las estimaciones de otros países, como el de consumo de productos siderúrgicos per capita en función de la renta y el de crecimiento del consumo en función del incremento del PNB, además de diferenciar entre los diversos tipos de productos siderúrgicos y rebajar las tasas de crecimiento teniendo en cuenta las grandes oscilaciones cíclicas soportadas habitualmente por esta industria, superiores a las de otros sectores ${ }^{6}$.

Desde el principio, las previsiones quedaron muy por debajo de la realidad y mostraron la excesiva prudencia de las autoridades, a pesar de que habían estimado índices anuales de incremento superiores al 10 por 100 para la década de 1960. Los cálculos de la siderurgia privada fallaron también estrepitosamente, alejándose de la realidad aún más que los públicos ${ }^{7}$. Se había previsto sobrepasar la barrera de los seis millones de toneladas de acero en 1971 y ello se logró en 1966. Este error tuvo consecuencias muy negativas para el comercio exterior y para la planificación de ENSIDESA, al proyectarse demasiado pequeña y tener que ir creciendo a trompicones y desarticulada ${ }^{8}$. La corrección del Programa Siderúrgico Nacional de 1966 tuvo como objetivo evitar que tal equivocación volviera a repetirse y, por ello, se elevaron considerablemente las previsiones, que luego serían retocadas ligeramente a la baja en las sucesivas adaptaciones hasta $1974^{9}$. Hasta este último año, gracias a la revisión efectuada en 1966, el acercamiento a la realidad fue notable. A partir de 1975, el distanciamiento fue, por el contrario, sobresaliente debido al carácter esencialmente imprevisible de la crisis. Veámoslo con unos cuantos guarismos porque ello resulta crucial para nuestra argumentación.

El consumo real en España pasó de un millón de toneladas de acero en 1953 (la misma cifra que en 1929) a 11,7 millones en 1974, creciendo a una tasa anual aproximada del 12,5 por $100^{10}$. Las sucesivas estimaciones para 1974 efectuadas desde la corrección de 1966 se habían situado entre 11,4 y 12,2 millones, así que se acercaron

6 Al ser materia prima de bienes de capital y de consumo duradero, muy sensibles a las variaciones cíclicas, el acero también lo es. Además, las variaciones de la demanda siderúrgica son mucho mayores que las oscilaciones del consumo real debido en parte al comportamiento de consumidores y almacenistas, que en épocas de crisis reducen al mínimo imprescindible los pedidos — trasladando los stocks a los productores- y en épocas de auge los elevan por encima de las necesidades reales ante el temor a quedar desabastecidos. De esta forma, agudizan las oscilaciones cíclicas (Espinosa (1972), p. 92; y Corella (1976), pp. 128-130. Según Gil (1970), pp. 102-104, este problema sería aún más grave en España debido al carácter especulativo y financieramente débil de sus almacenistas.

Aranguren (1965), p. 94.

Boyer (1975), p. 109. Además del error en las previsiones, el principal problema de ENSIDESA fue su carácter subsidiario con respecto a la siderurgia privada.

García Díez (1967), p. 50; y Elorduy (1970).

10 Del 13,5 por 100 entre 1953 y 1963, y del 11,5 por 100 entre ese año y 1974 (Buesa, 1983, p. 291). Los 11,5 millones de toneladas producidos en 1974 suponían $320 \mathrm{Kg}$ por habitante, equivalentes al 63 por 100 de la producción por habitante de la CEE. 
bastante, pero a partir de 1975 las previsiones comenzaron a fallar ${ }^{11}$. El Programa Siderúrgico Nacional preveía un incremento anual del 7,4 por 100 entre 1974 y 1981 y hubo una caída acumulativa del 4,6 por 100 , de forma que, en ese último año, los 18,8 millones previstos se convirtieron en tan sólo 8,4 reales ${ }^{12}$. Fue entonces cuando se volvió recurrente la crítica a las erróneas previsiones del Estado franquista, cegado por sus ansias de grandiosidad imperial. Sin embargo, lo cierto es que los técnicos de la Administración actuaron fuertemente afectados por el fatal pesimismo de la etapa anterior, empleando unas tasas de incremento considerablemente inferiores a las vividas en la década de 1960 — del 7,4 frente al 11,5 por 100- y sus estimaciones se vieron corroboradas por otras similares de UNESID, del International Iron and Steel Institute (IISI) para el conjunto de la siderurgia mundial ${ }^{13}$ y de los departamentos comerciales de AHV y USS, que previeron 16 millones para 1980 y 24 para $1990^{14}$. En definitiva, la distancia entre la estimación y la realidad a partir de 1975 no debe achacarse al procedimiento erróneo de la primera sino al carácter imprevisible de la segunda, afectada por una crisis de dimensiones inusuales. Evidencia los límites de las técnicas de previsión para aprehender la realidad, no las limitaciones de los técnicos del Estado ${ }^{15}$.

Frente a un consumo estimado de 18 millones en 1980, las fábricas no superarían los 12 cuando terminaran sus planes de expansión, por lo que, a la altura de 1970, resultaba evidente que España iba a sufrir en una década un déficit siderúrgico creciente, especialmente de productos planos. Entre los objetivos fundamentales de la Administración se hallaba el ahorro de divisas y la estimación efectuada calculaba en 3.600 millones de dólares el montante necesario para suplir la falta de producción

AFV, 892/04, Comisión gestora para el estudio de la IV PSI, p. 8; Corella (1976), p. 128; y Navarro (1988), p. 368. Albentosa y Zaragoza (1982), p. 82; y Fernández de Pinedo (2003), p. 43.

El IISI estimó un incremento anual del 4,5 por 100 para el consumo mundial de acero entre 1970 y 1985 , de forma que se pasaría de 594 millones a 1.144 en el último año citado. Para los países englobados dentro del grupo "Restantes territorios de Europa Occidental", entre los que se hallaba España, se calculaba una tasa del 5,3 por 100. Esto significaba que España alcanzaría en 1985 un consumo de 18,5 millones de toneladas de acero. AFV, 887/06, Resumen de preliminares de la IV PSI, julio de 1973.

AFV, 893/01; Espinosa (1972), p. 100; y Trillo (1974), p. 172. El objetivo de 18 millones de toneladas de acero para 1980 suponía alcanzar una producción por persona de cerca de $500 \mathrm{Kg}$, similar a la media de los países de la CEE en 1974. AGA, Industria, 6257, Informe sobre la 32ª sesión del Comité de la industria de la OCDE desarrollada en París desde el 16 al 18 de Marzo de 1977, p. 2; y Villar Mir (1974), p. 21.

Corella (1976), p. 122, ha hablado de las "ambigüedades e indeterminaciones" que rodean al estudio de la demanda de acero, que "se resiste a descubrir su comportamiento con respecto a las variables clásicas del análisis económico". Erróneas previsiones de demanda se encuentran también en la base de proyectos siderúrgicos luego paralizados en otros países mediterráneos como Francia, Italia, Marruecos, Argelia, Túnez, Libia y Egipto (Bernabé, 1983). En Australia existió un proyecto con importante participación japonesa para construir un complejo siderúrgico internacional de 10 millones de toneladas de capacidad. AGA, Industria, 6257, Industrie siderurgique. Project de rapport sur les tendances des investissements sidérurgiques, OCDE, 17/02/1977. 
nacional entre 1975 y 1980 si no se remediaba ${ }^{16}$. Además, la construcción de una nueva planta integral buscaba preparar a España para que contara con una siderurgia competitiva en el momento de entrar en el Mercado Común. Juan Ignacio Trillo, Consejero-Director General de Altos Hornos del Mediterráneo (AHM) en 1973, preveía la existencia de dos grandes grupos, el público, formado por ENSIDESA-UNINSA, con capacidad de 6,5 millones de toneladas, y el privado de AHV-AHM, con una producción de 8,5 millones y una planta de escala óptima de 6 millones: "La dimensión de estos grupos permitiría nuestra integración siderúrgica con Europa al disponer de unidades de producción y empresariales similares, lo cual, sin duda, hace posible un diálogo en condiciones de igualdad, circunstancia ésta de máxima importancia"17.

Las tres siderurgias integrales españolas estaban a punto de convertirse en dos por la absorción de UNINSA por ENSIDESA, de tal forma que ambas factorías asturianas, en Veriña y Avilés, serían de titularidad pública a partir de 1972 y su capacidad rondaría los 2,5 y 3,5 millones de toneladas, respectivamente, cuando hubieran terminado sus planes de ampliación hacia 1974. Las instalaciones de AHV, por su parte, se hallaban desperdigadas por la geografía vizcaína y valenciana y alcanzaban una producción de 2,2 millones ${ }^{18}$. Restricciones geográficas y tecnológicas limitaban seriamente sus posibilidades de crecimiento en Vizcaya, pero no ocurría lo mismo con Veriña, para la que algunos técnicos de ENSIDESA reclamaban una ampliación más ambiciosa en lugar de construir una nueva planta en otro lugar. Sin embargo, el Ministerio de Industria consideró desde el principio que el panorama siderúrgico español debía corregir su carácter marcadamente cantábrico equilibrándolo mediante la búsqueda de una nueva ubicación en algún punto del Levante o el sur. Las motivaciones comerciales inclinaban la decisión en el mismo sentido, al igual que el déficit global de productos siderúrgicos estimado, entre 6 y 8 millones de toneladas, coincidentes con el tamaño entonces considerado idóneo para una planta siderúrgica integral, a tenor de los ejemplos que podían encontrarse en los países vecinos $^{19}$.

La conveniencia de situar la nueva siderurgia en la costa quedaba fuera de toda duda y estaba inspirada en las experiencias recientes de diversos países ${ }^{20}$. El antiguo criterio de proximidad a una cuenca hullera o férrica había sido sustituido por la cer-

AFV, 892/04, Comisión gestora para el estudio de la IV PSI, p. 5; y Trillo (1974), pp. 167-169.

Trillo (1974), p. 172.

AFV, 879, Altos Hornos del Mediterráneo, s.a., s.f., documento elaborado por la Dirección de AHV.

AFV, 892/04, Comisión gestora para el estudio de la IV PSI; y 879, Altos Hornos del Mediterráneo, s.a., s.f., documento elaborado por la Dirección de AHV.

20 Véase Kipping, Ranieri y Dankers (2001), pp. 88-89, para la importancia de la localización costera en el éxito de los modelos italiano y holandés. 
canía al mercado y la disponibilidad de un puerto capaz de albergar los grandes buques portadores de materias primas, cuyo origen se encontraba en nuevos yacimientos férricos de África y Sudamérica y grandes países hulleros como Estados Unidos, la Unión Soviética, Polonia y Australia. De esta forma, "la siderurgia sobre el mar se conv(ertía) en auténtica necesidad" y países como Japón, sin contar con los inputs requeridos, habían podido transformarse en potencias siderúrgicas. Tarento, en Italia, y Dunkerque y Fos-sur-Mer, en el norte y el sur de Francia respectivamente, constituían otros ejemplos de proyectos de siderurgias integrales recientes situadas en la costa ${ }^{21}$.

El debate sobre el emplazamiento de la IV Planta se avivó en 1966, si bien el INI ya había hecho algunas indagaciones desde 1962. Numerosos organismos regionales y locales de toda España ejercieron una fuerte presión sobre el Ministerio de Industria para obtener tan suculenta inversión y llevaron la discusión a la prensa. Con ayuda del grupo italiano Cosider y de la austríaca Voest, se estudiaron los posibles emplazamientos de Bonanza (Guadalquivir), Algeciras, Huelva, Rota y Sagunto, y se consideraron como más aptos los dos últimos. En su reunión del 12 de agosto de 1966, el gobierno encargó profundizar en el estudio de viabilidad de la opción Sagunto a una comisión formada por los técnicos de Cosider y Voest, y un representante de cada una de las tres siderurgias integrales.

Sagunto partió de la posición más fuerte desde el principio y se convirtió en la opción a batir por parte de las demás candidatas. Alegaba en su defensa la existencia de su antigua fábrica con unas instalaciones que podrían servir para la nueva siderurgia integral, sobre todo en sus comienzos, ya que incluían el abastecimiento vía ferrocarril de los minerales de Sierra Menera, un puerto que, aunque pequeño, podía ser útil para las primeras descargas de material y servir de base para una ampliación posterior, la capacidad para ofrecer productos intermedios, talleres, fábrica de oxígeno y todo tipo de organismos ya establecidos para la asistencia social de los obreros y sus familias, $y$, fundamentalmente, mano de obra siderúrgica, técnicos cualificados y directivos preparados ${ }^{22}$. Además, resultaba una ventaja de primer orden su posición frente al mercado de productos siderúrgicos, puesto que podía abastecer en un radio de 400 kilómetros a los centros consumidores de Barcelona, Madrid, Zaragoza y Valencia, que absorbían el 62 por 100 de la demanda nacional ${ }^{23}$.

AS, IPIV, pp. 93, 116, 130 y 134; AGA, Industria, 6257, Industrie siderurgique. Project de rapport sur les tendances des investissements sidérurgiques, OCDE, 17/02/1977; Iranzo y Castellanos (1970), p. 76; y Corella (1976), pp. 106-107.

22 AFV, 565/02, Notas al estudio previo de la IV siderurgia, 20/10/1970, pp. 7-9.

$23 \mathrm{AFV}, 879$, Altos Hornos del Mediterráneo, s.a., s.f., documento elaborado por la Dirección de AHV; AGA, Sección Industria, Nota informativa sobre el emplazamiento de la IV PSI (Sur-Levante), 1966-67, pp. 3-4; y Casares (1976), p. 59. 
El posterior anuncio de la Ford Motor Company de implantarse en Valencia, con una demanda esperada de 200.000 toneladas anuales de chapa laminada en frío, vino a corroborar la idoneidad de Sagunto ${ }^{24}$.

Por encargo del INI, ENSIDESA realizó su propio estudio y apostó por la opción de la provincia de Cádiz una vez se hubo descartado la ampliación de Veriña. El argumento de los técnicos de esta empresa para criticar las ventajas de contar con las viejas instalaciones saguntinas estribaba en su obsolescencia y su pequeño tamaño. No podía condicionarse la implantación de la nueva siderurgia de seis millones de toneladas a la preexistencia de una fábrica que sólo llegaba a 600.000. Su puerto era pequeño e inutilizable para los cargueros de 100.000 a 200.000 toneladas que iba a necesitar la IV Planta, por lo que requería de una costosa remodelación. Además, vería incrementado el coste del transporte por mar entre 100 y 200 millones de pesetas al año con respecto a Cádiz debido al origen africano y sudamericano de la mayoría de los inputs. Por otra parte, los minerales de Sierra Menera no resultaban competitivos ni suficientes con respecto a los que podían obtenerse en el mercado internacional, los terrenos a expropiar eran inestables para su cimentación y tenían un precio más caro por tratarse de cultivos de regadío y el abastecimiento de agua dulce no estaba garantizado. Los técnicos de ENSIDESA apostaban, descartadas las opciones cantábricas, por situar la nueva siderurgia en la provincia de Cádiz, entre Chipiona y Rota, arguyendo que la necesidad de construir un nuevo puerto y la mayor distancia a los principales puntos de consumo con respecto a Sagunto quedaban sobradamente compensados por la mayor cercanía a las materias primas, la existencia de agua dulce abundante gracias al Guadalete y la idoneidad de los terrenos, baratos y consistentes para su cimentación ${ }^{25}$.

Las ventajas de Sagunto eran sin duda difíciles de cuantificar. ¿Cómo evaluar económicamente la conveniencia de disponer de mano de obra cualificada? El sobrecoste debido a terrenos, puerto y abastecimiento de agua dulce fue tasado por ENSIDESA en 8.570 millones de pesetas de inversión y 631 millones de explotación anual con respecto a la opción de Cádiz. Pero las necesidades de agua dulce, establecidas por algunos en torno a 100 hectómetros cúbicos para 6 millones de toneladas de

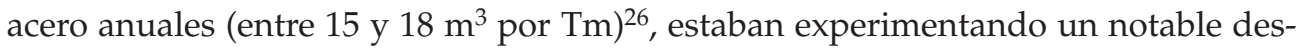

24 AS, IPIV, pp. 250-251; y AFV, Actas del Consejo de Administración (CA) de Altos Hornos de Mediterráneo (AHM), 07/05/1973. En su discurso ante la Junta General de Accionistas de AHM celebrada el 7 de mayo de 1973, Juan Miguel Villar Mir afirmó que la posibilidad de contar con un proveedor cercano de laminados había influido en la decisión de la Ford.

25 AGA, Sección Industria, Nueva siderurgia en la zona sur-levante. Informe en relación con la posible ubicación de la planta, presentado por ENSIDESA el 15 de julio de 1966. Véase también Navarro (1988), pp. 402-404.

26 El agua se necesitaba para refrigeración y lavado de gases de horno alto y coquerías. A pesar de los problemas de corrosión, la escasez de agua dulce llevaba a utilizar en la medida de lo posible agua de mar, 
censo gracias a los adelantos técnicos en su reutilización, de tal forma que la fábrica de Veriña lograría en su inauguración en 1971 rebajar esa cifra a menos de la mitad (7 $\mathrm{m}^{3}$ por Tm). No obstante, se trataba de un problema cuya solución quedaba ligada por el contrato de adjudicación a infraestructuras previstas por el Estado a largo plazo, como el canal Turia-Sagunto y el trasvase del Ebro. La empresa adjudicataria de la IV Planta se limitaría a pagar al Estado una peseta por metro cúbico de agua que recibiera ${ }^{27}$. En definitiva, Sagunto era suficientemente defendible desde los puntos de vista técnico y económico y resultaba aconsejable porque salvaba de una grave crisis a una ciudad industrial. Por último, resultó determinante su cercanía a los mercados, aspecto en el que la localidad valenciana ganaba por un amplio margen a todas sus competidoras ${ }^{28}$.

\section{La "gran decisión" de AHV: fase I y proyecto de fusión (1971-1975)}

Por sí solo, el objetivo de salvar las instalaciones obsoletas de la fábrica de Sagunto carecía de la suficiente entidad como para implicar a AHV en la IV PSI, aunque sí resultara un beneficio añadido de su localización ${ }^{29}$. Lo que llevó realmente a AHV a asumir la construcción de la IV Planta fue un motivo estratégico de mayor calado, el de conducir el crecimiento de la empresa a través de la nueva siderurgia integral, al tomar conciencia de que las instalaciones vizcaínas no tenían solución competitiva a largo plazo, constreñidas como estaban por la ría del Nervión y las ciudades de Sestao

otro motivo añadido para localizar la siderurgia en la costa (Millán, 1972). Basándose en el consumo de agua dulce de su fábrica de Avilés, ENSIDESA calculaba en 1966 unas necesidades de 0,6-0,7 m³/segundo/millón de Tm año, o, lo que es lo mismo, entre 113,5 y $132 \mathrm{Hm}^{3}$ al año para una planta de 6 millones de Tm. AGA, Sección Industria, Nueva siderurgia en la zona sur-levante. Informe en relación con la posible ubicación de la planta, presentado por ENSIDESA el 15/07/1966, p.17.

AFV, 892/04, Comisión gestora para el estudio de la IV PSI; AFV, 879, Altos Hornos del Mediterráneo, s.a., s.f., documento elaborado por la Dirección de AHV. El dato de Veriña se encuentra en Anónimo (1971), p. 112. En la base duodécima de la solicitud de autorización de estudios preliminares elevada al Ministro de Industria conjuntamente por los Presidentes de AHV y USS, Villar Mir y Edwin H. Gott, se estimaban unas necesidades de entre 4 y $6 \mathrm{~m}^{3}$ por Tm, lo que daría un total de 24-36 hectómetros, entre un cuarto y un tercio de lo calculado inicialmente. Pero hay que mirar estas cifras con precaución, porque quienes las ofrecieron tenían en ese momento un elevado incentivo para rebajarlas ante el ministro. AFV, 565. Espinosa (1972), p. 98. Una visión muy crítica con la opción de Sagunto puede consultarse en Navarro (1988), pp. 406-409.

29 Tampoco el de aprovechar la rentabilidad del tren de laminación en frío mediante la compra de los inputs necesarios a la francesa Fos-sur-Mer, tal y como aseveró Sánchez-Reyes, constituyó un factor esencial de dicha implicación, por más que no dejara de ser un buen negocio temporalmente. Sánchez-Reyes (1983). Véase también Navarro (1988), p. 412. 
y Baracaldo. Como le dijo posteriormente Juan Luis Burgos, Director Comercial de AHV, a su Presidente, Juan Miguel Villar Mir, se trató de tomar la "gran decisión" del grupo vasco, de "elegir entre un Altos Hornos grande o pequeño": "Se planteó entonces el dilema de ...continuar con un Altos Hornos para siempre pequeño y cada vez con menor peso dentro del sector siderúrgico, [o bien] decidir su crecimiento a través de la IV PSI, para convertir a la compañía en una empresa privada de otra escala y con un peso no sólo en el sector sino en la economía española, que, de otra manera, no podría ya alcanzar nunca". Si no se hacía así, la empresa tendría muchas posibilidades en el futuro de acabar siendo nacionalizada o expulsada del mercado. En la compañía vasca eran plenamente conscientes de que una existencia separada de la futura siderurgia integral "convertirá a ambas empresas en competidoras, con clara desventaja para $\mathrm{AHV}$, a medida que pasara el tiem$\mathrm{po}^{\prime \prime 30}$.

En esta "gran decisión", AHV contó con el soporte técnico de la United States Steel (USS) y el financiero de sus bancos accionistas, que vieron con aprobación la ambiciosa estrategia del grupo ${ }^{31}$. El apoyo técnico se concretó en tres contratos de asistencia firmados el 9 de junio de 1972. El primero renovaba el convenio de la USS y la empresa vasca de 1964 - retocado en 1969- con el objetivo de "la mejora y modernización de AHV", aplicable a las futuras instalaciones de Sagunto. Por el segundo, la USS se comprometía con AHM a prestar todo su concurso técnico para la construcción de la IV Planta. Mediante el tercero, la filial USS Engineers and Consultants hacía lo propio con su homóloga Altos Hornos Ingenieros Consultores (AHIN$\mathrm{CO}$ ), creada un mes antes por AHV y AHM para encarrilar todos los proyectos futu$\operatorname{ros}^{32}$. La USS recibiría en conjunto un millón de dólares al año por su consejo y asistencia técnica ${ }^{33}$. En cuanto al apoyo financiero de los bancos, en la constitución de AHM el 25 de octubre de 1971 — con un capital simbólico de un millón de pesetasparticiparon todos ellos, además de bancos y cajas locales, dejando un papel predo-

30 AFV, 884/11, carta de Burgos a Villar Mir, 07/11/1975; y AFV, 893/06, "Conflicto de intereses AHV-AHM".

31 Hay que tener en cuenta, además, que AHV acababa de salir de una difícil situación financiera que le había llevado a sufrir pérdidas millonarias hasta 1967. Durante la presidencia de Claudio Boada, que ocupó el cargo entre ese año y 1970 — en que fue sustituido por Juan Miguel Villar Mir—, se sanearon las cuentas y se renovaron equipos, de tal forma que en el momento de presentar la propuesta para la IV Planta se vivía un ambiente de optimismo en cuanto al futuro de AHV. AFV, 565, Evolución de la Cuenta de Pérdidas y Ganancias, 1967-1971.

32 Con un capital social de 10 millones de pesetas, AHINCO se dedicaría en una primera etapa a cubrir todas las necesidades de ingeniería de AHM, para después ofrecer sus servicios técnicos y de consultoría a cualquier empresa siderúrgica. AFV, Actas CA de AHM, 02/05/1972.

33 Sin contar los gastos de desplazamiento e impuestos que, por supuesto, también corrían a cargo de los españoles y que en la década de 1960 habían supuesto un montante mayor que los honorarios. AS, Contratos AHV/USS, AHM/USS y AHINCO/UEC. El cambio era de 63,48 pesetas por dólar en 1972. 
minante para AHV. La empresa vasca, que se reservaba el 46,2 por 100 de las acciones, la USS (con el 15 por 100) y seis bancos nacionales (con un 3,8 por 100 cada uno) reunían el 84 por 100 del capital y la consecuente mayoría de los puestos del Consejo de Administración, presidido por Villar Mir y contando con la asistencia de Antonio Garrigues Walker representando a la USS ${ }^{34}$. Cuando el concurso para la construcción de la IV Planta fue otorgado a AHM, el 10 de marzo de 1972, se procedió a ampliar el capital a 6.000 millones de pesetas manteniendo las proporciones acordadas en el momento de la constitución ${ }^{35}$.

El proyecto de la IV PSI presentado por AHM y aprobado por el gobierno calculaba una inversión de 126.665 millones de pesetas y se dividía en tres fases, previstas inicialmente para entrar en servicio en 1975, 1979 y 1982, aunque poco después se alargaron los plazos de las dos últimas a 1983 y $1989^{36}$. La verdadera siderurgia integral se reservaba para las fases II y III, con una capacidad de producción de seis millones de toneladas cuando estuviera concluida, y el acero producido se destinaba a la laminación de productos planos, de los que era deficitaria la economía española ${ }^{37}$. Las producciones vendibles estimadas aparecen resumidas en el Cuadro 1.

La fase I correspondía a la puesta en servicio del primer tren de laminación en frío de 1,2 millones de toneladas y la inversión necesaria para su construcción se

34 En concreto, la distribución del capital quedó como sigue: AHV, 46,2 por 100; USS, 15 por 100; los bancos de Bilbao, Central, Español de Crédito, Hispano Americano, Urquijo y Vizcaya, 3,8 por 100 cada uno; Banco de Valencia, 1 por 100; Caja de Ahorros de Valencia, 3,8 por 100; Caja de Ahorros Vizcaína, 3,8 por 100; Caja de Pensiones de Barcelona, 2,5 por 100; Caja de Ahorros del Sureste, 2,5 por 100; Caja de Ahorros Municipal de Bilbao, 1,65 por 100; Caja de Ahorros de Castellón, 0,5 por 100; y Caja de Ahorros y Socorros de Sagunto, 0,25 por 100. AFV, Acta de la Primera Junta General de Accionistas de AHM, $06 / 10 / 1971$.

35 El decreto por el que se sometía a concurso entre la iniciativa privada la construcción y explotación de la IV PSI se publicó el 1 de julio de 1971. Sólo se presentó AHM, evidentemente. AFV, 548/01, Información al Consejo de AHV del 6 de Octubre de 1976. Boyer afirma que el ministro de Industria, José María López de Letona, se vio obligado por la presión privada a otorgar la IV Planta a AHV en lugar de al INI, para compensar la concesión reciente al Instituto de la mayoría del capital de la refinería de petróleo de Tarragona (Boyer, 1975, pp. 104-105). Pero la localización en Sagunto ya había sido decidida por su predecesor en el cargo, Gregorio López Bravo, y aunque ello no implicaba directamente la concesión del proyecto a la empresa vizcaína — parece que su Presidente hasta 1970, Claudio Boada, era partidario de ceder las viejas instalaciones al Estado (Navarro, 1988, p. 406) - , sí la colocaba en una posición muy favorable en caso de desear finalmente llevarlo a cabo. De hecho, la verdadera razón de que ENSIDESA se opusiera a la opción de Sagunto en 1966 pudo muy bien haber sido que con esa localización disminuían sus posibilidades de hacerse con el control de la nueva siderurgia.

36 Casares (1976), p. 66.

37 Los consumos fundamentales de materias primas se estimaron en 4,3 millones de Tm de mineral de hierro y 2,1 de hulla coquizable para la fase II, y el doble para la fase III, al tiempo que se calculaban unas necesidades de compra de bobinas en caliente de 1,1 millones de Tm al año durante la fase I para alimentar el tren de laminación en frío. AS, IPIV, p. 162. 


\section{CUADRO 1}

PRODUCCIONES VENDIBLES ESTIMADAS DE LA IV PSI

(en miles de Tm)

\begin{tabular}{lccr}
\hline \multicolumn{1}{c}{ Producto } & Fase I & Fase II & Fase III \\
\hline Lingote de hierro & - & 141 & 133 \\
Desbastes de acero (slabs) & - & 35 & 885 \\
Bobina y chapa en caliente & - & 482 & 1.021 \\
Bobina y chapa en frío & 1.019 & 1.730 & 2.654 \\
Hojalata & - & 180 & 180 \\
Chapa galvanizada & - & - & 102 \\
Chapa pintada & 30 & 30 & 30 \\
Tubos soldados & - & - & 200 \\
\hline TOTAL* & $\mathbf{1 . 0 4 9}$ & $\mathbf{2 . 5 9 8}$ & $\mathbf{5 . 2 0 5}$ \\
\hline
\end{tabular}

(*) El cálculo de las cifras totales procede del documento original.

Fuentes: AS, IPIV, 163; y AFV, Fondo Altos Hornos de Vizcaya (AHV), 887/02, Estudio de AHINCO sobre la IV PSI, Agosto 1972.

estimaba en 14.900 millones de pesetas. En el proyecto se calculaba en un tercio de la inversión global de toda la IV Planta (es decir, 42.660 millones de pesetas) el montante al que ascendían las compras a realizar a empresas extranjeras ${ }^{38}$. En el caso de la fase I, la parte del león se la llevaron dos compañías americanas, Wean United y Westinghouse, al ser contratadas en julio de 1973 para suministrar los componentes esenciales del tren de laminación en frío ${ }^{39}$. Las instalaciones se detallan en el Cuadro 2.

Las tareas de construcción de la fase I se iniciaron en febrero de 1973 con el expediente de expropiación de los terrenos, un total de 210 hectáreas que en junio fueron ocupadas legalmente y en octubre comenzaron a ser removidas y explanadas. Durante 1974 y 1975 se levantaron las diversas instalaciones del tren de lami-

38 Se dividía la inversión total en las siguientes partes: un 26,2 por 100 para obra civil, un 18,9 por 100 para suministros nacionales de equipos e instalaciones, un 33,7 por 100 para suministros extranjeros, un 9,1 para montaje y el restante 12,1 por 100 para varios e imprevistos. AS, IPIV, p. 164.

El precio se elevaba a 986,2 millones de pesetas, 51,3 millones de dólares y 39.984.784 francos belgas. AFV, 900/05, Contrato suscrito entre AHM, y Wean United y Westinghouse (que incluía a la belga Ateliers de Constructions Electriques de Charleroi), 28/07/1973. Además del grupo Wean-Westinghouse, se presentaron ofertas de Japón, Italia e Inglaterra. AFV, Actas CA de AHM, 03/07/1973. 


\section{CUADRO 2}

INSTALACIONES Y CALENDARIO DE ENTRADA EN SERVICIO DE LA IV PSI

\begin{tabular}{|c|c|c|}
\hline Fase & Instalaciones & Año \\
\hline I & $\begin{array}{l}\text { - Tren de bandas en frío № } 1 \text { (1,2 millones de Tm/año) } \\
\text { - Línea de pintado ( } 35.000 \text { Tm/año) }\end{array}$ & 1975 \\
\hline II & $\begin{array}{l}\text { - Siderurgia integral, } 1^{a} \text { etapa ( } 3 \text { millones Tm/año; coquería, línea de sinterización } \\
\text { № } 1 \text {, horno alto no } 1 \text {, acería LD con } 2 \text { convertidores, colada continua) } \\
\text { - Tren de bandas en caliente ( } 3 \text { millones de Tm/año) } \\
\text { - Tren de bandas en frío № } 2 \text { ( } 1,1 \text { millones Tm/año) } \\
\text { - Línea de hojalata electrolítica ( } 200.000 \text { Tm/año) }\end{array}$ & 1979 \\
\hline III & $\begin{array}{l}\text { - Siderurgia integral, } 2^{\underline{a}} \text { etapa ( } 3 \text { millones Tm/año; duplicación } 1^{\text {a }} \text { etapa) } \\
\text { - Tren de bandas en caliente (ampliación hasta } 4,5 \text { millones Tm/año) } \\
\text { - Tren de bandas en frío № } 3(1,2 \text { millones Tm/año) } \\
\text { - Línea de galvanizado en caliente (110.000 Tm/año) } \\
\text { - Fábrica de tubos soldados ( } 200.000 \mathrm{Tm} / \mathrm{año})\end{array}$ & 1982 \\
\hline
\end{tabular}

Fuentes: AS, IPIV, 162.

nación en frío y las complementarias de agua, electricidad, aire y vapor ${ }^{40}$. El Cuadro 3 recoge las inversiones estimadas. Tales inversiones se realizaron en paralelo a la adquisición de la antigua factoría por Altos Hornos del Mediterráneo, prevista desde 1971 y ultimada el 13 de julio de 1974, en una operación digna de comentario. En primer lugar, AHV transformó jurídicamente la fábrica en una filial para desgajarla de su activo, y valoró el capital social de dicha filial en 3.300 millones de pesetas; en segundo, AHM se la adquirió por ese precio y procedió a extinguir su carácter de filial, incorporándola a su activo; en tercero, emitió obligaciones por la misma cantidad para pagar a AHV; en cuarto, estableció una separación contable de tal modo que las cargas financieras - intereses y amortización-corrieran a costa de la factoría saguntina y dejaran libre a la IV Planta; y en quinto y último lugar, subarrendó los servicios de AHV para que siguiera dirigiendo la factoría como había hecho hasta entonces. Y todo esto se hizo el mismo día, en un mismo acto notarial, con objeto de ahorrar gastos fiscales y con la obtención para AHV de un 


\section{CUADRO 3}

INVERSIONES ESTIMADAS DE LA IV PSI

(en millones de pesetas)

\begin{tabular}{lcrrr}
\hline \multicolumn{1}{c}{ Conceptos } & Fase I & Fase II & Fase III & Total \\
\hline 1. Terrenos y preparación & 1.300 & 400 & - & 1.700 \\
2. Modificación muelle actual & 115 & 165 & - & 280 \\
3. Nuevo puerto exterior & - & 2.250 & 235 & 2.485 \\
4. Manipulación y almacén primeras materias & - & 2.800 & 700 & 3.500 \\
5. Cok y subproductos & - & 5.300 & 3.300 & 8.600 \\
6. Sinterización & - & 2.300 & 1.700 & 4.000 \\
7. Hornos altos & - & 4.800 & 4.000 & 8.800 \\
8. Acería LD y planta cal & - & 3.700 & 1.250 & 4.950 \\
9. Planta oxígeno & - & 650 & 550 & 1.200 \\
10. Colada continua & - & 4.000 & 2.000 & 6.000 \\
11. Tren de bandas en caliente & - & 10.000 & 2.000 & 12.000 \\
12. Tren de bandas en frío & 7.850 & 6.950 & 6.800 & 21.600 \\
13. Recubrimientos & 350 & 3.000 & 700 & 4.050 \\
14. Tubos soldados & - & - & 1.900 & 1.900 \\
15. Energéticos y servicios & 2.755 & 18.000 & 7.915 & 28.670 \\
16. Repuestos & 550 & 1.800 & 900 & 3.250 \\
17. Fletes y seguros & 180 & 1.160 & 580 & 1.920 \\
18. Impuestos & 300 & 1.640 & 670 & 2.610 \\
19. Imprevistos & 1.500 & 5.000 & 2.650 & 9.150 \\
\hline TOTAL & 14.900 & 73.915 & 37.850 & $\mathbf{1 2 6 . 6 6 5}$ \\
\hline
\end{tabular}

Fuentes: AS, IPIV, 163; y AHV, 887/02, Estudio de AHINCO sobre la IV PSI, Agosto 1972.

buen precio por una fábrica adquirida en 1940, que mostraba desde hacía tiempo signos evidentes de obsolescencia, aun cuando podía seguir siendo rentable en años de buena coyuntura ${ }^{41}$.

$41 \mathrm{AFV}, 885 / 01$, Contrato de mandato entre las sociedades AHM y AHV para la gestión y dirección de la factoría de Sagunto; y AFV, 542/02, 544/01, 884/06, 884/08, 884/12, 887/03, 887/05 y 893/12. Tanto en 1974 como en 1975, Sagunto tuvo que desembolsar elevadas cantidades en concepto de cargas financieras debido a las obligaciones emitidas y, aún así, obtuvo modestos beneficios. ABBVA, Memoria de 1975, Acta de la Junta General de Accionistas celebrada el 07/03/1975. Es decir, la misma actividad de la fábrica financió la operación de compra-venta, algo que ya fue previsto desde los primeros estudios realizados por AHM en 1972. AFV, 544/01, 884/08 y 885/01; y AFV, Actas CA de AHM, 04/09/1973. Un juicio negativo de esta operación se encuentra en Navarro (1989), p. 24, nota. 
En realidad, el cambio de propiedad de la vieja factoría constituyó el primer paso de un ambicioso proyecto de fusión entre AHM y AHV, impulsado por quien fuera presidente de ambas compañías, Villar Mir, y apoyado por el Estado ${ }^{42}$. Se trataba de un aspecto esencial de la ya mencionada "gran decisión" de AHV, abocada a elegir entre dos opciones: crecer a través de AHM o mantenerse al margen, asumiendo una reducción inevitable de su participación en el mercado, con la posibilidad, nada remota, de ser expulsada por la nueva y más competitiva siderurgia integral mediterránea ${ }^{43}$. Además, los conflictos de intereses entre las fábricas vizcaínas y saguntinas fueron continuos desde 1973, y no era previsible que cesaran en el futuro si no se resolvían a través de su encauzamiento dentro de una entidad empresarial común. Tales conflictos se saldaron en contra de los intereses de AHM en la práctica totalidad de las ocasiones, y no por casualidad, como mostraremos a continuación.

Quizá el más llamativo de todos los casos fue el de Laminaciones de Lesaca, empresa ubicada en Navarra y dedicada a la laminación en frío que fue adquirida por AHV en $1973^{44}$. Tenía solicitada una autorización al Estado desde 1972 para la ampliación y renovación de sus instalaciones, que había llevado adelante a la espera de regularizar su situación en el futuro. Y es lo que se dispuso a hacer Villar Mir como presidente de AHV cuando se hizo con su control. Pero, para legalizar dichas instalaciones, debía dar su consentimiento AHM, ya que había quedado establecido en la concesión de la IV Planta que la empresa concesionaria debía otorgar su correspondiente nihil obstat, ya que la fase I consistía precisamente en laminación en frío. Y Villar Mir, como Presidente de AHM, lo otorgó, a pesar de que el incremento de la capacidad de Laminaciones de Lesaca iba a redundar inevitablemente en perjuicio de las expectativas comerciales de la IV Planta ${ }^{45}$. Lo que Villar Mir tenía en mente era el objetivo de que AHV controlara, a través de las instalaciones de Lesaca, Echévarri y las nuevas de la IV Planta, hasta dos tercios de la capacidad de laminación en frío de la siderurgia española. Además, tal y como explicó en una reunión de su consejo de administración, con la adquisición de Laminaciones de Lesaca se había evitado el riesgo

$42 \mathrm{AFV}, 884 / 06$, Escrito de la Dirección General de Industrias Siderometalúrgicas y Navales dirigido el 26 de octubre de 1973 a J. M. Villar Mir como Presidente de AHV y AHM.

$43 \mathrm{AFV}, 893 / 06$, Conflicto de intereses AHV-AHM.

44 La compra se ultimó el 24 de noviembre de 1973 por 3.300 millones de pesetas, y en las negociaciones desempeñó un papel importante el Banco Central, proveedor tradicional de crédito tanto de AHV como de Laminaciones de Lesaca. El Banco de Fomento, ligado al Central, concedió un crédito de 2.000 millones de pesetas a AHV para financiar parte del precio de la compra a seis años, en los cuales se calculó que las ventas de Laminaciones de Lesaca pasarían de 9.500 millones de pesetas en 1974 a 15.500 en 1979. AFV, 726/11, Cartas de Villar Mir a Alfonso Escámez, Presidente del Banco Central, fechadas los días 13/12/73 y 9/01/74.

$45 \mathrm{AFV}, 884 / 11$, Información para el Comité especial sobre la fusión de AHV-AHM; AFV, 884/12, Fusión AHV/AHM. Otros antecedentes documentales; y AFV, 893/06, Conflicto de intereses AHV-AHM. 
de que la comprara una compañía extranjera ${ }^{46}$. Pero la operación, aunque positiva para AHV, se hizo en contra de los intereses de AHM, y fue determinante para llevarla a término que Villar Mir empleara su doble presidencia.

Otro tanto ocurrió en la fábrica de Echévarri, en Vizcaya, con la instalación de una nueva línea de hojalata (estañado electrolítico), producto para el cual AHM tenía la exclusiva de toda ampliación para el mercado nacional ${ }^{47}$. Además, la vieja fábrica de Sagunto había sacrificado la buena coyuntura para productos estructurales en 1974 para proveer de planchones al tren de bandas en caliente de Ansio, también en Vizcaya, de donde salían las bobinas que abastecían la laminación en frío de AHV. Dentro de la empresa, muchos opinaban que el contrato de traspaso y gestión de la antigua factoría saguntina había sido la mejor forma que había tenido AHV de quitarse de encima unas instalaciones obsoletas a buen precio ${ }^{48}$. De hecho, la fusión no convenció a los accionistas de AHM que no lo eran de AHV y, así, los consejeros representantes de las entidades financieras valencianas mostraron hasta el final su disconformidad con la operación. Sin embargo, y pese a esta oposición, los consejos de administración de AHM y AHV aprobaron por mayoría la fusión de ambas compañías en las reuniones de los días 4 y 5 de diciembre de 1973, respectivamente, acordando que la mejor forma de llevarla a cabo era mediante la absorción de AHM por $\mathrm{AHV}^{49}$.

Durante 1974, Villar Mir dedicó parte de su tiempo a recoger las opiniones de consejeros y directivos acerca de la fusión y sus aspectos concretos. En la reunión del consejo de AHV celebrada el 4 de marzo se adoptaron cuatro importantes acuerdos. La sede social seguiría siendo la de AHV, la sociedad resultante se llamaría Altos Hornos de Vizcaya y del Mediterráneo, S. A., su consejo de administración tendría como máximo 29 miembros, además de los laborales — hasta entonces, en AHV había 24 consejeros sin contar los laborales, y 25 en AHM-, y el canje de acciones se realizaría, atendiendo a la cotización de AHV, en la proporción de 100 pesetas desembolsadas de AHM por 55 pesetas nominales de la empresa vizcaína. Sin embargo, cuando todo parecía estar encarrilado para que AHM fuera absorbida por AHV hacia fines

46 AFV, Actas del Consejo de Administración de AHV, 08/01/1974. Con posterioridad, el que entonces era Director Financiero de AHV, Burgos, explicó la compra de Laminaciones de Lesaca "por la necesidad de eliminar una competencia en el mercado de laminados en frío que había surgido sin autorización y que prorrumpía en el mercado asignado a la IV PSI". AHV (1982), p. 16. Supuso una inversión de 2.110 millones de pesetas. AFV, 542/01, Situación del mercado de la hojalata; y AFV, 544/03, Discurso del Sr. Presidente en la Junta General de Accionistas de AHV celebrada el 10 de Marzo de 1975. Al dedicarse a proveer de semiproductos a AHV, AHM perdía la posibilidad de elaborar productos de un mayor valor añadido. AFV, 893/06, Conflicto de intereses AHV-AHM. El precio obtenido por Sagunto en 1974 fue el mismo que el pactado por la adquisición de Laminaciones de Lesaca el año anterior, 3.300 millones de pesetas, en lo que parece una compensación de entrada y salida de recursos financieros para AHV. AFV, 542/02, 543/01 y 760/01; y AFV, Actas CA de AHM, 04/12/1973. 
de 1975, los representantes de los bancos comenzaron a mostrar sus dudas acerca de la operación. Unir la suerte de AHV a la de AHM era la clave de la estrategia de Villar Mir para garantizar el futuro de la empresa vizcaína, pero, por ello mismo, era fácil obtener una lectura inversa. A la vista del empeoramiento de la coyuntura siderúrgica, el consiguiente incremento del riesgo de la inversión en la IV Planta podía arrastrar a AHV en su conjunto si se producía la fusión, ya que ésta implicaba la subrogación de los compromisos adquiridos por AHM con el Estado, y alejaba la posibilidad de que el Instituto Nacional de Industria se hiciera cargo del proyecto en caso de un agravamiento de las dificultades. Y, como veremos a continuación, esto fue lo que finalmente ocurrió.

\section{La preparación de la fase II y su interrupción final (1975-1977)}

La idea de acelerar las inversiones de la fase II fue expuesta por Villar Mir en la reunión del Consejo de AHM celebrada el 1 de octubre de 1974. Según lo recogido por el secretario, el presidente de la sociedad explicó que "los cambios surgidos en el mundo respecto a las disponibilidades de acero, y en particular de bobinas en caliente, p(odían) crear dificultades de abastecimiento de materia prima para las instalaciones de la primera fase, lo que ha(bía) recomendado considerar la posibilidad de acelerar la puesta en marcha de la segunda fase. En principio, ha(bía) resultado de interés por parte del Ministro de Industria (...) Esto supon(ía) una inversión a realizar con mayor celeridad" 10 . Así pues, la decisión de acelerar la fase II no fue gubernamental, sino empresarial, y se tomó a la vista de las dificultades y oportunidades del mercado: el precio de las bobinas en caliente subió un 55 por 100 entre 1973 y 1975, de 10.500 pesetas a 16.272 por tonelada métrica, mientras que el precio de venta de los laminados en frío sólo lo hizo un 22 por 100, causando la consiguiente reducción del margen. Era de todo punto conveniente iniciar ya la fase II, pues ésta incluía como elemento esencial un tren de bandas en caliente destinado a cubrir las necesidades de bobinas del tren de laminación en frío. Además, lo que Villar Mir no consideró adecuado añadir en la reunión del Consejo de AHM fue que las ampliaciones llevadas a cabo en los últimos años en Laminaciones de Lesaca, Echévarri y ENSIDESA habían hecho disminuir las expectativas comerciales y de rentabilidad de la fase I por ser sus competidoras directas, y que resultaba muy conveniente que tal reducción fuera compensada por una más rentable fase II $^{51}$. 
La IV PSI estaba pensada desde su inicio para producir hasta seis millones de toneladas de acero cuando fuera concluida en la década de 1980, y este objetivo debía alcanzarse de forma escalonada a través de pasos intermedios, cuyos plazos de terminación se habían alargado en una revisión posterior de las previsiones iniciales. Tras la construcción del tren de laminación en frío, el programa de la fase II incluía todos los elementos de una siderurgia integral capaz de alcanzar la mitad de aquella cifra, tres millones de toneladas, y se dejaba para la fase III y definitiva la ampliación de la capacidad hasta los seis millones en que se calculaba el déficit de acero que iba a sufrir España hacia 1985. La aceleración del programa por Villar Mir supuso la división de la fase II en dos subfases de dos millones de toneladas cada una que entrarían en servicio a finales de 1979 y en enero de 1984, respectivamente. Representaba una inversión aproximada de 82.500 millones de pesetas en la subfase A y 43.500 millones en la subfase B, y constaba de los elementos recogidos en el Cuadro 4.

Así pues, ya en la fase II-A se dotaba a la IV Planta de todos los elementos para constituirse como una siderurgia integral, desde las instalaciones de cabecera hasta la laminación en frío, sustituyendo los hornos altos, convertidores y colada continua de la vieja fábrica de Sagunto e incorporando un fundamental tren de bandas en caliente inexistente hasta entonces, calculado para una producción anual de 4,5-5 millones de toneladas de bobinas, imprescindible para suministrar los inputs al tren de laminación en frío construido en la fase I, así como para cubrir las futuras necesidades del mercado nacional. Para la preparación de este proyecto, se creó en 1973 un equipo formado por los principales técnicos de AHV que trabajó durante dos años en permanente colaboración con los ingenieros de la USS, visitó plantas siderúrgicas de Estados Unidos, Rusia, Japón, Alemania, Francia, Inglaterra, Italia, Austria y Luxemburgo, y fue asistido, entre otras, por la francesa Sofresid y la japonesa Sumitomo. Entre 1974 y 1975, Villar Mir se reunió hasta siete veces con el Presidente de la USS para tratar el tema ${ }^{52}$. En definitiva, no fue el Estado franquista quien empujó inconscientemente a la siderurgia integral española hacia un desarrollo descabellado, sino que también la parte privada de dicha siderurgia previó erróneamente unas condiciones futuras óptimas para su expansión, amparada en ejemplos y técnicos extranjeros y financiada tanto por el ahorro nacional - bancos y cajas- como por inversores y prestamistas foráneos - la USS y el Equibank, principalmente-. Lo que sí hizo el Estado fue dar ayudas fiscales, conceder crédito público a través del Banco de Crédito Industrial —a un bajo tipo de interés, el 5,5 por 100, pero garantizándose hipotecariamente su devolución- y otorgar facilidades administrativas en permisos, licencias y expropiaciones. El Estado apoyó, por lo tanto, un proyecto de cuya 


\section{CUADRO 4}

INSTALACIONES DE LA FASE II DE LA IV PSI

\section{Fase II-A}

Fase II-B

- Instalaciones de cabecera

- Un horno Alto de 11,3 m. de diámetro de crisol

- Acería al oxígeno, con dos convertidores de $300 \mathrm{Tm}$ de capacidad

- Dos máquinas de colada continua

- Tren de bandas en caliente (TBC) de 2.235 $\mathrm{mm}$ de ancho
- Instalaciones complementarias cabecera

- Segundo Horno Alto idéntico al anterior

- Máquina de colada continua

- Ampliación del TBC

- Instalaciones de acabado de bobinas en caliente

- Ampliación de recocido en los trenes de laminación en frío

Fuentes: AHV, 545/02, Estudio de viabilidad de la Il fase de la IV PSI. Exposición ante el Consejo de AHV, 4/06/75; y 884/12, Fusión AHV-AHM. Otros antecedentes documentales. Septiembre 1975, p. 140.

bondad muy pocos dudaban, porque garantizaba el abastecimiento nacional de bobinas en caliente, reducía el déficit exterior, potenciaba la industria nacional de bienes de equipo y, sobre todo, aseguraba a España la posesión de una siderurgia integral competitiva a nivel mundial de cara a tener éxito en su futura integración en el Mercado Común ${ }^{53}$.

Y es que el optimismo en los ambientes rectores empresariales tanto nacionales como internacionales reinó hasta el primer semestre de 1975 a pesar de la crisis desatada por el encarecimiento de las materias primas desde finales de 1973. Resulta significativa, en este sentido, la carta que el 1 de marzo de 1974 envió un representante de la USS en el Consejo de AHV al Presidente, Villar Mir. En ella le presenta su dimisión por problemas de salud, pero considera cumplida su misión al ver "a Altos Hornos pleno de vitalidad, juventud, nuevas ideas y muy buenos beneficios" además de "en muy buenas manos", de tal forma que "la confianza en su porvenir es muy gran$\mathrm{de}^{\prime \prime 54}$. Y en diciembre de 1974, George Moore, ex-presidente del First National City Bank (Nueva York), declaró en Madrid que Sagunto sería "la siderúrgica más competitiva del mundo y produciría el acero más barato del mundo" 55 . más, no se salían de lo que había sido norma corriente en el resto de países siderúrgicos, sobre todo en lo concerniente a la concesión de créditos a interés preferente. Véase Guereca (1966).

55 Entrevista con D. Ignacio Hidalgo de Cisneros, Metales y Máquinas, enero-febrero de 1975, p. 13. 
También los congresos anuales del IISI constituyen un buen indicador del ambiente que se respiraba en el sector, y Villar Mir asistía a tales reuniones para luego informar al Consejo de AHV. En la que tuvo lugar en Munich en octubre de 1974, los responsables de las principales empresas siderúrgicas del mundo mostraron su confianza en el porvenir inmediato de la siderurgia. El Secretario General del IISI trazó un panorama de demanda creciente a la vista de las alzas experimentadas en los años previos: partiendo de los 710 millones de toneladas de 1974, la demanda de acero se elevaría progresivamente en el decenio siguiente hasta superar los mil millones hacia 1985, mientras que los proyectos de nuevas instalaciones conseguirían aumentar la producción en 160 millones, que servirían para cubrir sólo la mitad del incremento esperado de la demanda. A la vista de estos datos, los proyectos de diversos países para elevar sus producciones resultaban ajustados, por lo que no es de extrañar que el gobierno español, el consejo de AHV con su presidente a la cabeza y la USS se mostraran confiados ${ }^{56}$.

Las cosas comenzaron a variar de aspecto en el primer trimestre de 1975 por la caída de la demanda y la elevación de los costes. En España, mal que bien, se mantuvieron las cifras, con un débil aumento sobre el mismo período del año anterior del 2,1 por 100 del consumo aparente, que por primera vez quedó levemente por debajo de las previsiones del Programa Siderúrgico Nacional ${ }^{57}$. A pesar de que Villar Mir anunció los problemas de encarecimiento y abastecimiento de materias primas a los que se había tenido que enfrentar la empresa en 1974, todavía se mostró optimista en su discurso ante la Junta General de Accionistas de AHV celebrada el 10 de marzo, proponiendo un dividendo del 8,5 por 100 gracias a los beneficios del año anterior, así como una ampliación del capital social de una acción nueva por cada diez viejas, basándose en la "excelente salud financiera" de la empresa, con un fondo de maniobra de 5.000 millones de pesetas y sin créditos a corto plazo pendientes de devolución $^{58}$. Pero en la reunión que el IISI celebró en Osaka el 7 de abril de 1975 el optimismo de ocasiones anteriores dio paso a la incertidumbre. Villar Mir fue apuntando las opiniones de los diferentes responsables presentes en la conferencia. Tanto el estadounidense como el francés apostaron por una recuperación a partir de septiembre, mientras los delegados de Italia y Holanda se mostraban pesimistas y los de Japón, Alemania y Bélgica no se atrevían a realizar pronósticos. En líneas generales, se esperaba un consumo similar al del año anterior para el ejercicio en curso ${ }^{59}$.

\footnotetext{
$56 \mathrm{AFV}, 543 / 03$

57 AFV, 545/02, Informe sobre la coyuntura del sector siderúrgico en el mes de Marzo de 1975; y Actas de UNESID, 26/05/75. El consumo aparente se calcula a partir de la producción nacional, el material relaminable, el saldo del comercio exterior y la variación de los stocks de las fábricas siderúrgicas. AFV, 544/03, Discurso del Sr. Presidente en la Junta General de Accionistas de AHV celebrada el 10 de Marzo de 1975. AFV, 545/01 y 545/02.
} 
En tales circunstancias, delegados de la USS y de AHV mantuvieron durante el año al menos tres reuniones en Madrid y Pittsburgh para analizar la marcha de la economía y la política españolas, y preparar los primeros pasos de la segunda fase de la IV Planta Siderúrgica Integral. En realidad, dichas reuniones fueron convocadas por los bancos de Bilbao, Vizcaya y Central, poderosos accionistas de AHV, preocupados por el cambio de criterio en la construcción de la IV Planta y el proyecto de fusión entre AHV y AHM. Ante el responsable de ambos proyectos, Villar Mir, los representantes de los bancos expusieron a los socios americanos sus dudas acerca de la conveniencia de acelerar la construcción de la IV Planta y, sobre todo, de unir ambas empresas. A este respecto, argumentaron que, en caso de dificultades, podría obtenerse la participación del INI si AHM se mantenía independiente, haciendo valer su condición de adjudicataria oficial del proyecto, pero no si pasaba a formar parte del grupo de AHV, cuyos 40.000 accionistas, además, verían incrementado el nivel de riesgo de sus acciones. Sin embargo, todos los participantes en las reuniones mantuvieron expresamente su apoyo a la IV Planta y su intención de acudir a la ampliación de capital necesaria para su financiación en la proporción correspondiente, a condición de que se hiciera un nuevo estudio de viabilidad y rentabilidad del proyecto ${ }^{60}$.

En un informe elevado el 13 de octubre de 1975 al Comité Especial sobre la fusión AHV-AHM, la Dirección Financiera de AHV apostó fuertemente por mantener los proyectos en curso con el argumento de que la crisis vivida ese año era tan pasajera como la de 1971, consecuencia de ciclos siderúrgicos de 4 ó 5 años, con perspectivas claras de reactivación en los años siguientes, tal y como había ocurrido en la etapa 1972-1974: "El estar en un momento alto o bajo en el ciclo siderúrgico es un hecho coyuntural, mientras que la fusión es una decisión estructural"61. En 1975, la producción de acero de la CECA se situó al nivel de 1968, un 20 por 100 menos que en 1974, y la utilización de la capacidad de producción bajó del 85 por 100 en 1974 al 65 por 100 en 1975. La producción mundial cayó a 651 millones de toneladas, el 92 por 100 de la del año anterior, y en España el consumo aparente sufrió un descenso del 14,5 por $100^{62}$. Sin embargo, y aunque las previsiones de demanda del IISI no se habían cumplido para ese año, la Dirección Financiera de AHV no tenía duda de que el mundo sufriría escasez de acero en la década de 1980. Por ello, la empresa no debería cejar en el empeño de construir la IV Planta ni separarse de AHM, pues tal

60 AFV, 884/12, Fusión AHV-AHM. Otros antecedentes documentales, Septiembre de 1975, pp. 91-112.

$61 \mathrm{AFV}, 884 / 11$, Información para el Comité especial sobre la fusión de AHV-AHM, p. 4.

$62 \mathrm{AFV}, 760 / 03$, Nota sobre la reunión extraordinaria del Consejo de Dirección de UNESID con el Director General de Industrias Siderometalúrgicas y Navales el día 15 de Diciembre de 1975 y Acta de la reunión del Consejo de Dirección del día 26 de Enero de 1976. 
alternativa daría paso a la entrada del INI en el proyecto. Y concluía: “La pérdida de posición relativa en el sector siderúrgico sería a costa de aumentar consecuentemente la de nuestro principal competidor, y la escasísima dimensión relativa de AHV conduciría probablemente a su nacionalización" ${ }^{\prime 63}$.

Pero los últimos meses de 1975 fueron prolijos en acontecimientos. Los representantes de la USS habían expuesto en las reuniones citadas sus dudas acerca de la evolución política española ante la desaparición inminente de Franco. Tanto José Ángel Sánchez Asiaín, representante del Banco de Bilbao en AHV, como Villar Mir, les habían manifestado su confianza en la madurez del país y en su democratización, de la mano de quien estaba destinado a ser el nuevo Jefe del Estado. Cuando Juan Carlos I mantuvo la confianza en Carlos Arias Navarro como Presidente del Gobierno, Villar Mir fue llamado a ocupar la Vicepresidencia del Gabinete, cargo que compatibilizó con el de ministro de Hacienda entre su nombramiento en diciembre de 1975 y su salida del gobierno en julio de 1976. Mientras tanto, la transición de un régimen a otro provocaba el retraso en la toma de decisiones en lo relacionado con la IV Planta, y para cuando Villar Mir, como era costumbre, volvió al consejo de AHV tras su corta aventura política, no ocupó de nuevo la presidencia sino una vocalía, desde la que fue testigo de un cambio de rumbo en la estrategia de la empresa que suponía una clarísima rectificación de la que él había llevado hasta fechas recientes. El nuevo presidente, Javier Benjumea — un representante de los bancos, lo que no deja de ser significativo-, decidió olvidarse de "la gran decisión" de AHV, abandonar las iniciativas tomadas hasta entonces sobre la expansión y diversificación de las actividades del grupo, y concentrar su esfuerzo en evitar el incremento de las pérdidas $^{64}$. Se abría paso la opción por un "AHV pequeño".

Un análisis confidencial de las acciones siderometalúrgicas fechado en noviembre de 1975 y basado en parte en los informes del IISI subrayaba la temporalidad de la crisis, apuntaba una clara mejoría de las empresas para 1976 y concluía con la promesa de "una perspectiva muy satisfactoria para muchos inversores y especuladores" $^{\prime \prime}$. No hubo tal. Los ejercicios de 1976 y 1977 no fueron para la siderurgia española mejores que el anterior. El consumo nacional de acero se estancó en 10 millones de toneladas, incumpliendo ya claramente las previsiones del Programa Siderúrgico Nacional —un 24 por 100 menos en 1976- Las actas de los Consejos de Adminis-

63 Recuérdese que AHV sufría graves limitaciones de espacio para desarrollar futuros planes de expansión de sus instalaciones en Vizcaya. En 1976, el Secretario General de UNESID, Rafael Cereceda, aludía al mismo argumento de los ciclos siderúrgicos de 4 ó 5 años para concluir que la situación y perspectivas de la siderurgia española eran buenas y que la paralización de las inversiones en el sector traería graves consecuencias en los años venideros (Cereceda, 1976). Sobre los ciclos siderúrgicos puede verse Larraz del Río (1976). AFV, 545/03.

Grupo Barcelonés de Especialistas (1975), p. 69. 
tración de AHM y de AHV reflejaron la amplitud creciente de las dudas de los socios. Al mismo tiempo que, en cumplimiento de mandatos anteriores, se realizaban inversiones para la implantación de la fase II-A de la IV Planta, se preparaba el camino para la sustitución de AHV por el INI en el accionariado de AHM, olvidando el proyecto de fusión de las dos empresas.

El año 1976 fue el primero en que el nuevo tren de laminación en frío pudo ofrecer productos a la venta y se siguió preparando la fase II con proyectos de ingeniería y expropiaciones de terrenos ${ }^{66}$. El Ministerio de Industria autorizó la división en dos subfases el 31 de marzo, previendo la puesta en marcha de la fase II-A para el 31 de diciembre de 1979, la de la II-B para el 31 de diciembre de 1984 y la de la fase III para fines de la década de 1980. Con la autorización conseguida, y con la aprobación del proyecto de expropiación de 1.100 hectáreas de terreno por el Ministerio de la Vivienda en aquel mismo mes de marzo, la dirección de AHM procedió a preparar las negociaciones con el Banco de Crédito Industrial, el Eximbank de Japón y el de Estados Unidos, entidades financieras de Inglaterra y Francia y bancos nacionales para obtener los créditos necesarios. El Consejo de Administración de AHM se mostraba optimista sobre la posibilidad de que les fueran concedidos, a la espera de que se tomara una decisión definitiva sobre la inversión que se demoraba más de lo previsto ${ }^{67}$.

En octubre de 1976 se habían expropiado 850 hectáreas de terreno y se habían invertido en la fase II-A en torno a 1.400 millones de pesetas, y se esperaba pagar en lo que quedaba de ejercicio otros 920 millones en expropiaciones e ingeniería, mientras los accionistas discutían el último informe de viabilidad de la IV Planta, elaborado un mes antes. En enero de 1977, el Presidente de AHM intentaba obtener el respaldo del Ministro de Industria para el proyecto, imprescindible para lograr el apoyo financiero posterior del Banco de Crédito Industrial. Entretanto, AHM preveía para el final de 1977 un agujero de 12.000 millones, causado por el desequilibrio en el intercambio de semiproductos, la acumulación de pérdidas y las cargas financieras de las inversiones. De forma un tanto críptica, en la reunión del 3 de mayo, Benjumea anunciaba al Consejo de AHM que "se prev(eía) llegar a una mayor coordina-

66 Para 1977 se preveía una producción de laminados en frío de 350.000-400.000 toneladas, y unas necesidades de bobinas de 530.000, que esperaban comprarse a la fábrica de AHV en Ansio (20 por 100), Japón (60 por 100), Italia (15 por 100) y USS (5 por 100). AFV, 548/01, Información al Consejo de AHV del 6 de Octubre de 1976. AFV, Actas CA de AHM, 04/05/76. El optimismo del Consejo de AHM no era de extrañar si se considera que la emisión de 4.000 millones de pesetas de obligaciones para la fase I, anunciada el día 1 de noviembre de 1975, fue cubierta en su totalidad en mes y medio, fundamentalmente por las cajas accionistas de AHM, destacando la Caja de Ahorros Vizcaína con 500 millones de pesetas y la Caja de Ahorros Municipal de Bilbao con 300. AFV, Actas CA de AHM, 17/03/76 y Junta General de Accionistas celebrada el 23/06/76. Por su parte, el Eximbank contaba con una amplia experiencia en la financiación de proyectos siderúrgicos. Cass (1968), pp. 54-55. 
ción entre la siderurgia nacional (pública) y la privada, especialmente Sagunto", y en la del 6 de junio se abandonaba oficialmente el proyecto de fusión con $\mathrm{AHV}^{68}$.

Lo que se estaba ventilando en esos meses era el futuro de AHM. El Ministro de Industria ordenó la creación de una Comisión de Estudio para dictaminar sobre la IV Planta, formada por el Director General de Industrias Siderometalúrgicas y Navales, el Director de la USS Mission, el Presidente de ENSIDESA y el Consejero Delegado de AHV. Se hizo un viaje a Pittsburgh, el Presidente de USS se entrevistó con el Ministro de Industria, y, finalmente, se llegó al acuerdo de construir sólo el tren de bandas en caliente, dejando el resto de instalaciones para una coyuntura más propicia. Se decidió que el Instituto Nacional de Industria entrara en el accionariado de AHM y que AHV saliera de la empresa ${ }^{69}$. Pero la situación de la siderurgia integral española comenzaba a ser preocupante. Los problemas financieros y la falta de liquidez llevaron a AHM a no pagar la nómina de octubre. La debilidad de la demanda obligó a reducir de tres a dos turnos la producción de laminación en frío, previendo la posibilidad de llevarlo a un solo turno y preparando la solicitud para un expediente de regulación de empleo. AHV mostraba una imperiosa necesidad de cobrar la deuda de casi 8.000 millones de pesetas que tenía reconocida de AHM, así como de separarse por completo tanto de la propiedad como de la gestión de la empresa saguntina. Y se decidió la disolución de AHINCO, la empresa de ingeniería creada para desarrollar el proyecto de la IV Planta ${ }^{70}$.

Por fin, el Consejo de Ministros celebrado el 28 de octubre de 1977 acordó dejar en suspenso la fijación de la fecha límite para la terminación de la fase II. En otras palabras, el inicio de la construcción de la fase II-A podía esperar: era el fin de la IV Planta Siderúrgica Integral de Sagunto ${ }^{71}$. En la reunión del Consejo de AHM del 16 de diciembre, Benjumea presentó el Proyecto VIS (Viabilidad Interna Sagunto) que, con una inversión de 33.000 millones de pesetas, preveía la continuación de la antigua fábrica y la construcción del tren de bandas en caliente. El día 27 de diciembre

68 AFV, Actas CA de AHM, 18/01/77, 01/03/77, 03/05/77 y 06/06/77.

69 AFV, Actas CA de AHM, 26/07/77.

70 AFV, Actas CA de AHM, 06/09/77 y 02/11/77. La deuda contraída por AHM con AHV, aceptada por ambas partes, ascendía a 7.884 millones de pesetas a 31 de diciembre de 1977. Se trataba del saldo de una cuenta que comprendía todas las transacciones habidas entre las dos empresas desde que las instalaciones de Sagunto pasaron a ser propiedad de AHM. En grandes cifras, AHM aparecía como proveedor de semiproductos y productos por 3.726 millones, pero como comprador de bobinas por 2.507, y AHV había realizado pagos en nombre de AHM por casi 12.000 millones (carbones, minerales, fletes, seguros, proyecto FAS,...), de los que se le habían devuelto sólo 3.840. A ello había que añadir casi 1.000 millones de intereses por el plazo transcurrido. AFV, 896/20, Regularización del saldo de la cuenta AHV-AHM al 31-12-77, 16 de Marzo de 1978.

71 En realidad, el proyecto se mantuvo formalmente en pie hasta que la Dirección General de Industrias Siderometalúrgicas y Navales anuló los plazos para la ejecución de las inversiones pendientes en enero de 1980. Viaña (1991), p. 219. 
presentó su dimisión ante el Consejo y fue sustituido por Ignacio Hidalgo de Cisneros, a quien sus compañeros agradecieron lo que, en circunstancias tan difíciles, sin duda significaba un verdadero "acto de servicio"72. En el transcurso de 1978 se llegó a un acuerdo definitivo con el INI por el cual éste se convertía en accionista único de AHM, tras llevar a cabo una operación acordeón con las acciones consistente en reducir el capital a cero para compensar pérdidas y ampliarlo a continuación a 12.000 millones de pesetas. De ellos, el INI suscribía 4.000 y los restantes 8.000 correspondían a la conversión de créditos pendientes, que serían pagados por el Instituto a los acreedores una vez hubiera hecho una valoración definitiva de la fábrica. De esa forma, el acuerdo evitaba la socialización de pérdidas ya que el Estado se hacía cargo del futuro de Sagunto a cambio de que la empresa privada asumiera el coste del pasado, algo que fue aceptado "de mala gana" en los círculos financieros de Bilbao ${ }^{73}$.

Por su parte, la Comisión de Estudio creada por el Ministerio de Industria para analizar la fase II de la IV PSI acabó transformándose en un comité para estudiar las medidas de apoyo a las tres siderurgias integrales, ENSIDESA, AHV y AHM, compuesta por los ministerios de Industria, Economía y Hacienda, y un representante de cada compañía. Esta comisión debía establecer dos tipos de medidas, unas a corto plazo, para solucionar los problemas inmediatos de liquidez de las empresas, y otras a largo, para asegurar su viabilidad futura ${ }^{74}$. Nacía de este modo la política de reconversión de la siderurgia integral.

\section{Conclusiones}

La clave del fracaso de la IV PSI se encuentra en el estudio comercial sobre el cual se asentaba todo el proyecto. La previsión de la demanda esperada de acero en España falló estrepitosamente porque, a la altura de 1971, resultaba imposible prever la llegada de la futura crisis, y poco probable imaginar el carácter estructural que tendría ésta una vez se desencadenó en 1975. Los informes del Ministerio de Industria se hacían de común acuerdo con las empresas a través de UNESID y en conexión directa con lo que se pensaba y hacía en la siderurgia internacional, a través del Instituto Internacional del Hierro y del Acero y de otros mecanismos. Pero, sobre todo, lo que se olvida cuando se critica la falta de respuesta ante la recesión en 1975 es que, en ese año, casi todos los analistas estaban convencidos de su corta duración, tanto en España

\footnotetext{
72 AFV, Actas CA de AHM, 16/12/77 y 27/12/77.

73 Ley 60/1978, publicada en el BOE de 25/12/1978; Anónimo (1978), pp. 52-53; y Navarro (1988), pp. $424-425$.

74 AFV, Actas CA de AHM, 06/09/77 y 16/12/77.
} 
como en el resto del mundo. Expertos siderúrgicos, financieros, analistas bursátiles y gobiernos coincidieron en apostar por una pronta recuperación. Sólo en 1976 se hizo patente la profundidad de la crisis. Quienes elaboraron las estimaciones fueron acusados posteriormente de no haber previsto la depresión, algo que evidentemente no podían hacer.

La gran apuesta de la dirección de AHV presidida por Villar Mir desde 1970 fue la IV Planta de Sagunto, a través de la cual habían de hallar solución los problemas de crecimiento de la empresa vizcaína, cercada geográficamente para su expansión en las instalaciones de la ría de Bilbao. Desde que decidieron involucrarse en la IV Planta - "la gran decisión" de AHV— Villar Mir y su equipo vieron claramente la necesidad de dar los pasos requeridos en cada momento, amparados hasta 1974 por una coyuntura favorable, de cuyo cambio de signo no se quiso tomar nota hasta que hubo transcurrido demasiado tiempo. Así, el empeoramiento de las expectativas comerciales y la baja rentabilidad de la fase I, motivados tanto por hechos externos -el incremento del precio de las bobinas - como por decisiones internas - Laminaciones de Lesaca, Echévarri-, empujaron a AHV y sus socios a acelerar los planes de la fase II y a impulsar su fusión con AHM, cuyo primer eslabón fue el traspaso de la vieja fábrica de Sagunto en condiciones ventajosas para los vizcaínos. Pero el cambio de tendencia en 1975 y el agravamiento de la coyuntura a partir de entonces, que coincidió con la salida de Villar Mir de la presidencia de ambas compañías, empujó a la empresa vasca y a sus bancos accionistas - y finalmente a la USS - a abandonar la "gran decisión" y optar por "un AHV pequeño".

Por todo ello, la insistencia en la década de 1980 de explicar el fracaso de la IV PSI por las veleidades faraónicas del régimen franquista constituye un ejercicio de "presentismo" que conviene revisar. A tenor de lo expuesto, debemos concluir que el franquismo se convirtió en chivo expiatorio de una situación crítica para la siderurgia integral española. Juzgar la idoneidad de las medidas adoptadas en 1983 desbordaría los límites de este trabajo. Adelantamos, sin embargo, que el haber atribuido la génesis de la IV PSI al faraonismo franquista creó un ambiente proclive al desmantelamiento de la siderurgia saguntina.

\section{Bibliografía}

ALBENTOSA, Luis, y ZARAGOZA, José (1982): “Estructura y política siderúrgica. De la acción concertada a la política de reconversión", Información Comercial Española, 591, p. 75-84.

ALTOS HORNOS DE VIZCAYA (1982): AHV, Nueva edad, Bilbao, Altos Hornos de Vizcaya. 
ANÓNIMO (1971): "Inauguración de la factoría siderúrgica de UNINSA en Veriña", Economía Industrial, 92, pp. 106-113.

-(1978): "Medidas de saneamiento para la siderurgia integral", Economía Industrial, 178, pp. 45-53.

ARANGUREN, Félix (1965): “Algunas aclaraciones al artículo del Sr. Paris Eguílaz: "Aspectos de la política siderúrgica»", Información Comercial Española, 380, pp. 93-95.

BERNABÉ MAESTRE, José María (1983): “¿Es necesaria una cuarta planta siderúrgica integral?", Noticias, 8 de julio de 1983.

BINDA, Verónica (2005): “Entre el Estado y las multinacionales: la empresa industrial española en los años de integración a la CEE", Revista de Historia Industrial, 28, pp. 117-153.

BOYER, Miguel (1975): "La empresa pública en la estrategia industrial española: el I.N.I.", Información Comercial Española, 500, pp. 94-123.

BUESA BLANCO, Mikel (1983): El Estado en el proceso de industrialización. Contribución al estudio de la política industrial española en el período 1939-1963, Tesis doctoral inédita, Madrid, Universidad Complutense de Madrid.

CASARES CÓRDOBA, Emilio (1976): "La IV Planta Siderúrgica Integral", Economía Industrial, 151-152, pp. 59-67.

CASS, A. Carl (1968): "Relaciones de Eximbank con el desarrollo de la siderurgia mundial (Análisis de la industria siderúrgica en el II Simposio interregional de las Naciones Unidas)", Economía Industrial, 58, pp. 51-61.

CATALAN, Jordi (2002): "La madurez de una economía industrial, 1936-1999", en DE LA GRANJA, José Luis, y DE PABLO, Santiago (coords.), Historia del País Vasco y Navarra en el siglo XX, Madrid, Biblioteca Nueva, pp. 197-223.

-(2003): "La ruptura de posguerra y la industrialización, 1939-1975", en NADAL, Jordi (dir.), Atlas de la industrialización de España, 1750-2000, Barcelona, Crítica, pp. 233-384.

CAVALLÉ PINÓS, Carlos (1975): El sector siderúrgico español, Pamplona, Universidad de Navarra.

CERECEDA, Rafael (1976): "Momento actual de la siderurgia española", Información Comercial Española, 514, pp. 157-162.

CORELLA AZNÁREZ, Ignacio (1976): "Financiación de la industria siderúrgica", Hacienda Pública Española, 41, pp. 97-152.

El País, 18 de julio de 1983.

ELORDUY, José Manuel (1970): “Hay que revisar el Programa Siderúrgico Nacional", Actualidad Económica, 31 de enero de 1970.

ESPINOSA, Carlos (1972): "La industria siderúrgica española", Información Comercial Española, 464, pp. 91-109.

FERNÁNDEZ DE PINEDO, Emiliano (2003): “Desarrollo, crisis y reconversión de la siderurgia española a través de una empresa vizcaína, AHV (1929-1996)", Ekonomiaz, Revista Vasca de Economía, 54, pp. 28-51. 
GARCÍA CRESPO, Milagros; VELASCO, Roberto, y MENDIZÁBAL, Arantza (1981): La economía vasca durante el franquismo. Crecimiento y crisis de la economía vasca: 1936-1980, Bilbao, La Gran Enciclopedia Vasca.

GARCÍA DÍEZ, Juan Antonio (1967): “La siderurgia, problemas y perspectivas en este sector", Información Comercial Española, 404, pp. 39-55.

GIL LARRÍNAGA, Ignacio (1970): “Aspectos de una posible integración de la siderurgia española en la Comunidad Económica Europea", Economía Industrial, 80, pp. 93-108.

GRUPO BARCELONÉS DE ESPECIALISTAS (1975): Las acciones siderometalúrgicas. Estudio técnico analítico confidencial, Barcelona (s.n.).

GUERECA TOSANTOS, Luis (1966): "La financiación de la industria siderúrgica", Economía Industrial, 27, pp. 17-29.

INSTITUTO NACIONAL DE INDUSTRIA (1984): "Sagunto fue un sueño de grandeza", Pueblo, 8 de marzo de 1984.

IRANZO GONZÁLEZ, Adolfo, y CASTELLANOS AGUILAR, Victoriano (1970): "Tendencias de la industria siderúrgica mundial: sistemas de producción, dimensiones y localización", Economía Industrial, 80, pp. 73-92.

KIPPING, Matthias; RANIERI, Ruggero, y DANKERS, Joost (2001): “The emergence of New Competitor Nations in the European Steel Industry: Italy and the Netherlands, 1945-1965", Business History, 43, 1, pp. 69-96.

LARRAZ DEL RÍO, Francisco (1976): “Los ciclos de la industria siderúrgica. Su incidencia, a corto y a largo plazo, en la rentabilidad de las empresas", Economía Industrial, 151-152, pp. 81-86.

MILLÁN BARBANY, Gregorio (1972): “Industrias siderúrgicas y mecánicas", Economía Industrial, 105, pp. 73-91.

NAVARRO ARANCEGUI, Mikel (1988): La política de reconversión industrial en España: el caso de la siderurgia, Tesis doctoral inédita, Bilbao, Universidad de Deusto.

-(1989): Crisis y reconversión de la siderurgia española, 1978-1988, Pasajes-Madrid, Junta del Puerto de Pasajes/MOPU.

SÁNCHEZ-REYES Y DE PALACIO, Carlos (1983): “El error de Sagunto”, El País, 22 de septiembre de 1983.

TRILLO Y LÓPEZ MANCISIDOR, Juan Ignacio (1974): “La IV P.S.I. Su integración en el territorio e influencia sobre el desarrollo de Sagunto", Información Comercial Española, 485, pp. 165-180.

VIAÑA REMIS, Enrique (1991): Políticas industriales en sectores maduros. El caso de la siderurgia integral española (1980-1983), Tesis doctoral inédita, Madrid, Universidad Complutense de Madrid.

VILLAR MIR, Juan Miguel (1974): "Horizonte 80 de la siderurgia española", Economía Industrial, 125, pp. 15-23. 